Conclusion Introduction of tobacco free policies in all educational buildings and at school gate parameters will create a completely smoke-free environment for children.

Outcomes The local health promotion department supported the implementation of smoke-free schools gates. Links were made with the Tobacco Free Ireland programme. https://hse.ie/ eng/about/Who/TobaccoControl. The first Smoke Free School Gates in the Republic of Ireland was launched in April 2018 in Ballina, Co. Mayo. The local Foroige youth group in conjunction with X-Hale created a documentary about the local school. Outcomes were evaluated since tobacco and smoke free school gates was implemented https://youtu.be/ jINcfxdoKeI.

\section{P257 AFTERNOON TEA-CHING - TO TEACH OR NOT TO TEACH}

Nicola Hanlon*, Karen Cunningham, Suzanne Kernan. Renal Service, Temple Street Childrens University Hospital, Dublin, Ireland

10.1136/archdischild-2019-epa.607

Nicola Hanlon, Clinical Educational Facilitator \& Karen Cunningham Clinical Nurse Manager 2, SMC/Renal unit TSCUH. Background Workforce deficiencies and variations within the health care system have called for a significant evaluation on how nurses are trained to deal with challenges within the health care setting. Despite these changes nurses must advance and develop in order to provide practice that is safe, reliable , of high quality and evidence based. An effective clinical learning environment is crucial for the development of specific clinical skills and competencies through theoretical, practical knowledge and understanding (Chuan \& Barnett 2012, Cibulka 2011,Roxburgh et al 2008, Heath 2002). In order to improve current practices, reliable inter professional collaboration is essential. Health professionals from all backgrounds should work together as a team in order to improve patient outcomes, provide a standard of care that is evidence based leading to an enhancement of the quality of the service (Lestari et al 2018).

Aims and objectives To Explore the feasibility of afternoon teaching sessions and examine methods of increasing the MDT'sknowledge whilst portraying the development and effectiveness of IPE through the use of daily "Afternoon TEAching sessions' at ward level with a multi-disciplinary approach to teaching.

Methods/Interventions 2-4 planned weekly teaching sessions. Organised on a monthly basis by the clinical educational facilitator, facilitated at ward level.

Results/Findings After 3 months of teaching sessions (62 sessions including unplanned sessions) questionnaires were distributed to participants $(n=16) .100 \%$ of those questioned felt that all teaching sessions were valuable to their practice. $100 \%$ agreed that the sessions were facilitated effectively. 94\% suggested areas in which they would like teaching sessions such as arterial line, peritoneal dialysis, resus scenarios. . $100 \%$ questioned had attended a variety of sessions at ward level.

Conclusions Clinical Educators and Department managers have a fundamental role in facilitating Inter professional Education (IPE). Our data shows that all staff found teaching sessions accessible, relevant, practical, inclusive. All staff indicated an interest in sustaining teaching sessions as a form of IPE on an ongoing basis at ward level. IPE is a cost effective, feasible and beneficial method of enhancing MDT knowledge on all relevant topics.

\section{P258 ATTITUDES, BENEFITS AND BARRIERS TO PARTICIPATING IN MANDATORY CONTINUING PROFESSIONAL DEVELOPMENT SCHEMES IN PAEDIATRICIANS IN IRELAND}

Holly Rose Hanlon*, Lucia Prihodova, Thelma Russell, Deirdre Donegan, Ann O'Shaughnessy, Hilary Hoey. RCPI, Dublin, Ireland

\subsection{6/archdischild-2019-epa.608}

Background A formal mandatory system of continuous professional development (CPD) in the form of Professional Competence Schemes (PCS) was introduced for all doctors working in Ireland in 2011 and who are not enrolled in a postgraduate paediatric training programme. The Royal College of Physicians of Ireland (RCPI) provides general and specialist schemes for Paediatricians working in Ireland.

Purpose of study: To explore their attitudes, perceived benefits and barriers to participation in PCS in order to improve their future CPD engagement.

Methods All doctors $(\mathrm{n}=456)$, Fellows (generally consultants) $n=150$ (33\%), Non-Fellows (generally junior doctors not in training programmes) $\mathrm{n}=306(67 \%)$, registered in the paediatrics RCPI PCS in $2017 / 18$ were invited to complete an anonymous online survey exploring their attitudes, perceived benefits and barriers in participating in PCS. Descriptive statistics and ANOVA were used to analyse the data.

Results The survey was completed by 187 paediatricians (41\% response rate; $41.7 \%$ male, $58.3 \%$ female,) Fellows $\mathrm{n}=44$ (24\%), Non Fellows $n=141$ (76\%). All PCS requirements were met by $91 \%$ of Fellows and by $57 \%$ of Non Fellows. A further $14.4 \%$ were new entrants to the scheme. Majority had positive view on participation in PCS: only 5\% reported it as being a bad idea, with those meeting requirements having significantly more positive attitudes than new starters $(F=3.76$, $\mathrm{p} \leq 0.05)$. The positive impact of CPD was reported predominantly on patient care related skills: patient care (85\%), patient safety $(81.6 \%)$, and teaching $(75.6 \%)$. The main challenges included difficulty accessing quality $\mathrm{CPD}$ activities (32.2\%), time to participate in CPD activities (29.9\%) and time to record their CPD activities (23.3\%). Those who met PCS requirements reported significantly fewer barriers compared to those who did not $(\mathrm{F}=5.44, \mathrm{p} \leq 0.01)$, however no differences were observed in terms of perceived benefits of PCS participation.

Conclusions and recommendations The findings indicate that while Irish paediatricians value CPD and perceive various benefits from their participation, they also experience various barriers to meeting PCS requirement. This was particularly observed in junior hospital doctors and in those who have recently joined the PCS Nonetheless, all doctors attributed multiple benefits from taking part in PCS, especially in relation to improving patient care. Paediatrics in Ireland view participation in mandatory CPD as positive and beneficial, however they also encounter barriers, possibly preventing them from deriving the full benefits of their CPD engagement. Greater support is required for junior doctors and new entrants. 